\title{
Dependence on molecular weight of acid-base properties of humic and fulvic acids
}

\author{
A. Falzoni ${ }^{1}$, R. Seeber ${ }^{1}$, D. Tonelli ${ }^{1}$, C. Ciavatta ${ }^{2}$, C. Gessa ${ }^{2}$ and D. Montecchio ${ }^{2}$ \\ ${ }^{1}$ Dipartimento di Chimica Fisica e Inorganica, Università di Bologna, \\ Viale Risorgimento, 4 - 40136 Bologna, Italy \\ ${ }^{2}$ U.C.I. - Scienze e Tecnologie Agroindustriali ed Agroambientali, Istituto di Chimica Agraria, \\ Università di Bologna, Via Berti Pichat, 10 - 40127 Bologna, Italy
}

\begin{abstract}
The organic matter of Irish peat of Sphagnum was extracted with $0.1 \mathrm{M} \mathrm{NaOH}$ and separated into humic (HA) and fulvic (FA) acids. Afterwards, HA and FA fractions were obtained at different nominal molecular weight using a tangential ultrafiltration system. The behaviour of such fractions has been studied both in acid and alkaline solutions. Solutions at different ionic strength have been titrated under different conditions and the resulting curves have been elaborated through a computer program based on a bimodal Gaussian distribution. The typical parameters $\left(\mathrm{pK}_{\mathrm{A}}\right.$ mean value and dispersion degree) of the two main groups of HA and FA acidic functionalities have been determined.
\end{abstract}

Key words. Humic acids - fulvic acids - fractionation $-\mathrm{pK}_{\mathrm{a}}$ distributions.

\section{Introduction}

Humic Substances (HS) are heterogeneous macromolecules deriving from biological, chemical and physical degradation of organic matter. They are ubiquitous in soils, sediments, and natural waters. Their importance is due to the ability to bind and mobilise metals and anthropogenic organic species. HS do not belong to any well defined category of chemical compounds and they can not be defined in terms of precise structural properties [1]. The wide spectrum of characteristics of these substances implies a high degree of molecular weight dispersion (from 1000 to 1000000 dalton) [2]. Since HS are amorphous, polydisperse colloids, it is only possible to determine an average molecular weight, which depends on the measurement method applied. HS show a strong cation exchange capacity, generally from 5 to 12 $\mathrm{mmol} \mathrm{g}{ }^{-1}$, which is due to the presence of functional groups such as carboxylic and phenolic acids. Because of the huge variety and number of acidic groups, HS acid-base properties can not be described by discrete values of $\mathrm{pK}_{\mathrm{a}}$. It was suggested that the acidity of HS has to be mainly ascribed to the presence of carboxylic groups, with $\mathrm{pK}_{\mathrm{a}}$ values resembling a Gaussian distribution, and to further weaker acidic moieties, like phenolic groups, some carboxylic acids and alcoholic groups deriving from carbohydrate residues, whose $\mathrm{pK}_{\mathrm{a}}$ belong to a second Gaussian distribution [3]. Owing to these characteristics of the acidic functionalities in $\mathrm{HS}$, a continuous bimodal Gaussian distribution model, characterised by two mean values $\left(\mathrm{pK}_{\mathrm{A}, 1}\right.$ and $\left.\mathrm{pK}_{\mathrm{A}, 2}\right)$ and two relevant standard deviations $\left(\sigma_{1}\right.$ and $\left.\sigma_{2}\right)$ [4] was adopted for describing their acidic properties and by fitting at best the experimental data.

HS from soil are conventionally distinguished, according to their solubility in aqueous solutions, into humic acids

Received Mar ch 18, 1998; revised May 15, 1998; accepted May 27, 1998. 
(HA), insoluble below $\mathrm{pH} 2$, fulvic acids (FA), soluble at any $\mathrm{pH}$, and humine, which is the fraction that results insoluble at any $\mathrm{pH}$ and that can not therefore be extracted from the natural sources [2]. The study of the properties of HA and FA was in the recent past generally made on the fractions obtained on the basis of the different solubility characteristics, that have been just described, without any further treatment to make the system less complex. Recent studies $[5,6]$ have shown that structures and charge distributions of HA and FA vary according to the molecular weight.

In order to analyse a system which can be better defined, we separated HA and FA extracted from a sample of peat into fractions with different ranges of nominal molecular weight, through a tangential ultrafiltration system. The acidbase properties of the resulting fractions were investigated by potentiometric titrations.

\section{Experimental}

\section{Reagents}

All chemicals were of analytical reagent grade (Merck, Darmstadt, Germany). Ultrapure water was obtained from a Milli-Q system (Millipore, Milford, MA, USA).

\section{Extraction procedure}

HA and FA were extracted from an Irish peat of Sphagnum, whose main characteristics are the following: total organic carbon: $52.3 \%$; $\mathrm{pH}$ : 4.8 ; total nitrogen: $0.72 \%$; total phosphorus: $0.03 \%$; ash content: $4.5 \%$. The extraction procedure was carried out according to the following steps:

- $2 \mathrm{~kg}$ of peat were suspended and stirred in $40 \mathrm{~L} 0.1 \mathrm{M}$ $\mathrm{NaOH}$ aqueous solution for 5 hours at room temperature $\left(20^{\circ} \mathrm{C}\right)$ under nitrogen atmosphere;

- the resulting suspension was centrifuged at $7000 \mathrm{rpm}$ for $1 \mathrm{~h}$;

- the supernatant was filtered first through a mixture of cellulose ester (Millipore, pore size $0.8 \mu \mathrm{m}$ ) and subsequently through a $0.2 \mu \mathrm{m}$ filter, using a Minitan S System (Millipore). The liquid obtained was dialysed against distilled water (Molecular Weight Cut Off (MWCO) membrane $=500$ dalton) and the $\mathrm{HA}$ were precipitated at $\mathrm{pH}$ 1.5 by adding a $6 \mathrm{M} \mathrm{HCl}$ solution;

- the HA fraction was obtained by centrifugation at 7000 rpm for $30 \mathrm{~min}$, the supernatant containing both FA and the non-humified material;

- HA were solubilised using small amounts of $0.5 \mathrm{M} \mathrm{NaOH}$ solution until neutral $\mathrm{pH}$, filtered through a $0.2 \mu \mathrm{m}$ filter and dialysed;

- the solution obtained was lyophilised and stored under vacuum and silica gel;

- the FA solution containing also the non-humified material was passed through a polyvinylpyrrolidone column, in order to separate the soluble FA from the other material. FA were then released by eluting with $0.1 \mathrm{M} \mathrm{NaOH} \mathrm{[7];}$

- the FA solution was filtered through a $0.2 \mu \mathrm{m}$ filter and dialysed;
- finally, the FA aqueous solution was lyophilised and the solid FA was stored under vacuum and silica gel.

\section{Fractionation procedure}

The separation of FA and HA into different fractions according to the average molecular weight was carried out through the following steps:

- a $0.005 \mathrm{M} \mathrm{NaCl}$ solution of FA or HA at a concentration of about $3 \mathrm{~g} \mathrm{~L}^{-1}$ was prepared [8];

- the separation was accomplished using tangential ultrafiltration, through a Spectrum MP3 (Spectrum, Houston, TX, USA) pump, fitted with membranes of suitable diameter.

According to the membrane cut-off, the fractions obtained were as those reported in Table I. Every sample was dialysed against water at 500 dalton and then lyophilised. The reliability of this procedure has been already tested for HA [9]. Any further details can be found in the same reference [9].

\section{Potentiometric Titrations}

The titrations were carried out using a Radiometer automatic apparatus, consisting of a VIT90 titrator, a ABU93 automatic burette and a SAM90 sample station. The precision of the dispenser was $\pm 0.1 \mu \mathrm{L}$ and the accuracy was $\pm(0.4+3 \times$ $V) \mu \mathrm{L}$, where $V$ stands for the actual amount of reagent dosed, expressed in $\mathrm{mL}$. The titration temperature was controlled at $25 \pm 0.1{ }^{\circ} \mathrm{C}$ using a thermostatic bath and the beaker was sealed with a cap, provided with suitable holes for electrodes, thermometer, burette, and $\mathrm{N}_{2}$ inlet and outlet.

The electrodes used were a saturated calomel reference electrode and a glass membrane electrode (Radiometer, Copenhagen, Denmark). We could verify that a daily calibration, using $\mathrm{pH}$ 4.01, 7.00 and 9.18 Radiometer buffer solutions, was effective. The titrant solutions were prepared from $\mathrm{HCl}$ and $\mathrm{NaOH}$ standard solutions.

The HA and FA solutions were equilibrated for two hours at the titration temperature; they were de-aerated for $15 \mathrm{~min}$ with $\mathrm{N}_{2}$ before as well as during the titration. The ionic strength was buffered with $0.05 \mathrm{M}$ or $0.005 \mathrm{M} \mathrm{NaCl}$. The concentration of freeze dried HA or FA was $0.6 \mathrm{~g} \mathrm{~L}^{-1}$. Two different procedures were followed in the titrations: in a former one (direct titration), after acidification down to $\mathrm{pH}$ 2.50, $0.1 \mathrm{M} \mathrm{NaOH}$ titrant was used; in a latter one (reverse titration) $\mathrm{pH}$ was raised up to $10.5-11.0$ by adding $0.5 \mathrm{M}$ $\mathrm{NaOH}$, and $0.1 \mathrm{M} \mathrm{HCl}$ was used as titrant. In both cases the

Table I. Formal HA and FA fractions, as resulting from filtration through different MWCO membranes.

\begin{tabular}{cc}
\hline$H A$ & $F A$ \\
\hline MWCO $>300000\left(\mathrm{HA}_{300}\right)$ & $\mathrm{MWCO}>20000\left(\mathrm{FA}_{20}\right)$ \\
$100000<\mathrm{MWCO}<300000\left(\mathrm{HA}_{100}\right)$ & $10000<\mathrm{MWCO}<20000\left(\mathrm{FA}_{10}\right)$ \\
$50000<\mathrm{MWCO}<100000\left(\mathrm{HA}_{50}\right)$ & $5000<\mathrm{MWCO}<10000\left(\mathrm{FA}_{5}\right)$ \\
$20000<\mathrm{MWCO}<50000\left(\mathrm{HA}_{20}\right)$ & $1000<\mathrm{MWCO}<5000\left(\mathrm{FA}_{1}\right)$ \\
$10000<\mathrm{MWCO} 20000\left(\mathrm{HA}_{10}\right)$ & $500<\mathrm{MWCO}<1000 .\left(\mathrm{FA}_{0.5}\right)$ \\
$5000<\mathrm{MWCO}<10000\left(\mathrm{HA}_{5}\right)$ & \\
$500<\mathrm{MWCO}<5000\left(\mathrm{HA}_{0.5}\right)$ & \\
\hline
\end{tabular}


titration started after an equilibration time of $15 \mathrm{~min}$. Different titrant addition speeds $\left(0.003\right.$ to $\left.0.01 \mathrm{~mL} \mathrm{~min}^{-1}\right)$ were tested.

The calculation of the parameters (mean value $\mathrm{pK}_{\mathrm{A}}$ and standard deviation $\sigma$ ) for a single or a bimodal Gaussian distribution of the $\mathrm{pK}_{\mathrm{a}}$ values of the different HA or FA fractions was performed by the computer program PGAUSS [10], based on a refining iterative fitting procedure. According to the bimodal Gaussian distribution approach, each group of acidic moieties is described by the error function:

$$
\mathrm{d} C / C_{\mathrm{L}}=1 / \sigma(2 \pi)^{1 / 2} \exp \left[-1 / 2\left(\mathrm{pK}_{\mathrm{A}}-\mathrm{pK}_{\mathrm{a}}\right)^{2} / \sigma^{2}\right] \mathrm{dpK}
$$

where $\mathrm{d} C / C_{\mathrm{L}}$ is the infinitesimal mole fraction of ligands with acidity constants within $\mathrm{dpK}_{\mathrm{a}}$ interval.

The FORTRAN program run on a IBM RISC 6000 workstation.

\section{Results and discussion}

The stability of HS in alkaline solutions is a debated question, since literature supporting instability [11-14], as well as stability [15-17] can be found. According to our findings, poor stability appears to be a general characteristic, since it was observed both in the HA and in the FA different fractions. In figures 1 and 2 the $\mathrm{pH}$ decrease following the addition of base to HA and FA solutions at $\mathrm{pH}=7$, is shown. The instability at alkaline $\mathrm{pH}$ is revealed, in the course of a titration, by the decrease of $\mathrm{pH}$ which takes place right after the increase following the addition of base titrant in this region. This behaviour can not be explained by a reaction with atmospheric $\mathrm{CO}_{2}$, because the titrations were carried out under slight $\mathrm{N}_{2}$ overpressure. On the contrary, the portion of the titration curve in acidic environment appears to be more reliable, the equilibrium being reached more rapidly and no $\mathrm{pH}$ drift being evidenced.

The instability of the solution at high $\mathrm{pH}$ leads to lack of coincidence between forward (starting from acid conditions) and backward (from alkaline $\mathrm{pH}$ ) titration curves, also observed when wide time intervals were interposed between two subsequent titrant additions. Not surprisingly, the separation between the two curves is higher, the higher the titrant addition velocity is. As an example of the differences between the two curves, figures $3 \mathrm{a}$ and $\mathrm{b}$ show the relevant plots for $\mathrm{HA}_{300}$ and $\mathrm{FA}_{0.5}$, respectively. The acid-base behaviour of HS is hence definitely more complex than that of simpler substances. A possible explanation for the differences between direct and reverse titrations can be given assuming that in the former case the starting conformation is likely to be spherocolloidal, while the final conformation is quasi-linear; the opposite is supposed to hold in the latter case [8]. Based on this assumption, the rates of the protonation-deprotonation reactions have to be different on the different conformations; furthermore, conversion from one to the other conformation should be a slow process. Although, when possible, we performed both direct and reverse titrations and elaboration of the relevant curves, the data reported throughout the paper, unless otherwise specified, are relative to titrations carried out starting from FA and HA fractions under the acidic form. A typical titration curve, together with

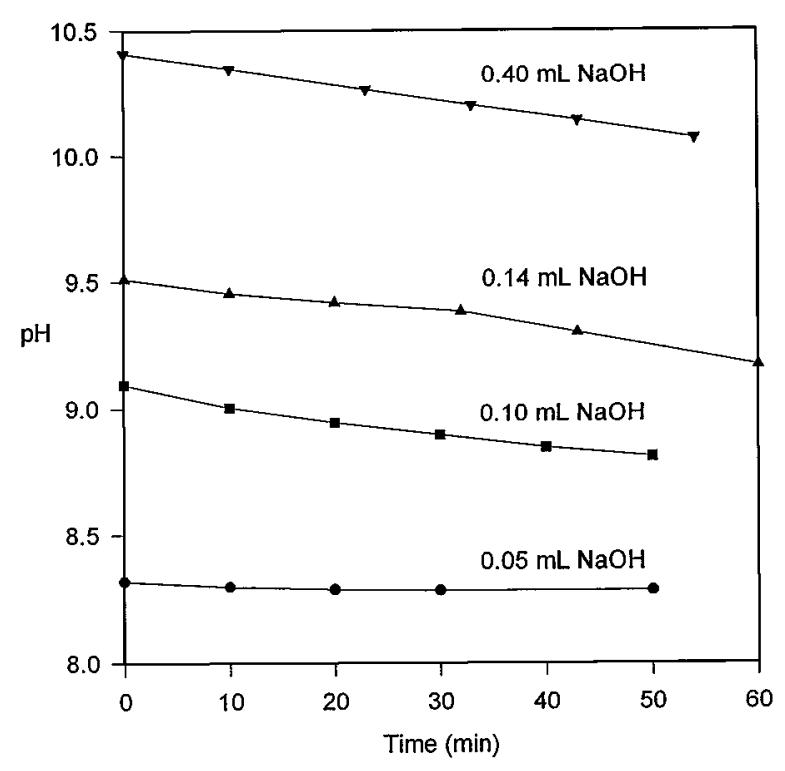

Fig. 1. $\mathrm{pH}$ drift following the addition of different amounts of $0.05 \mathrm{M} \mathrm{NaOH}$ to equal volumes $(20 \mathrm{~mL})$ of $600 \mathrm{ppm} \mathrm{HA}_{300}$ solutions.

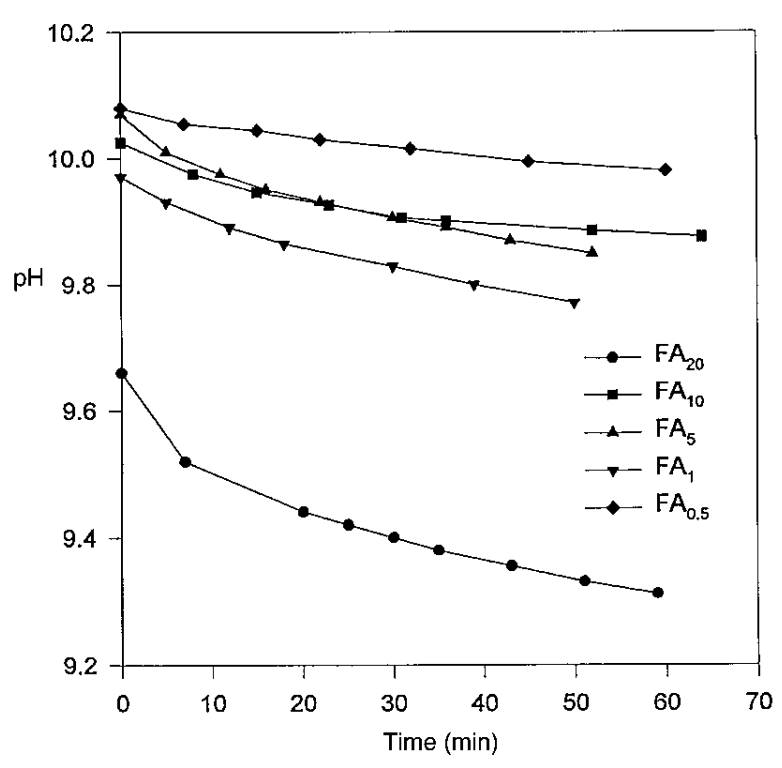

Fig. 2. $\mathrm{pH}$ drift following the addition of equal amounts $(0.5 \mathrm{~mL})$ of $0.05 \mathrm{M} \mathrm{NaOH}$ to equal volumes $(20.0 \mathrm{~mL})$ of solutions of different $\mathrm{FA}$ at a $600 \mathrm{ppm}$ concentration.

the corresponding calculated $\mathrm{pK}_{\mathrm{a}}$ bimodal distribution, is reported in figure 4.

The results obtained by elaborating the titration data with the program PGAUSS are reported in tables II and III. All titrations were repeated three times; the amounts of HA samples corresponding to fractions with MWCO lower than 50000 were however too small to allow for more than a single titration, so that we are forced not to report any data for these fractions. On the contrary, the quantities of the different FA fractions were sufficient to perform any kinds of measurements necessary to obtain faithful results. The poor 

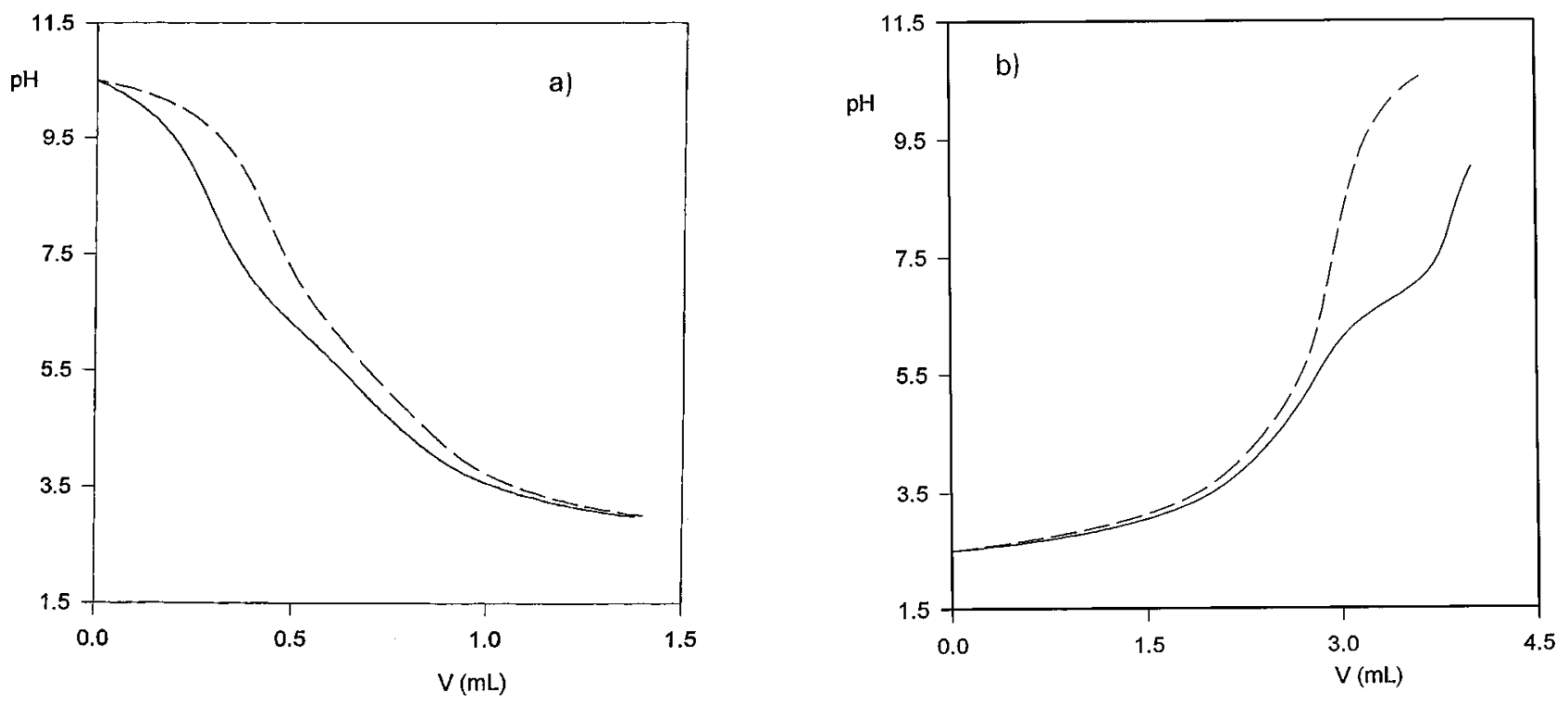

Fig. 3. Titration curves of 600 ppm $\mathrm{HA}_{300}$ (a) and $1,000 \mathrm{ppm} \mathrm{FA}_{0.5}$ (b) solutions. Continuous lines: basic titrant added (direct titrations); dashed lines: acid titrant added (reverse titrations). The abscissa scale factor is the same for both titrants, but the values reported refer to acid (a) and basic (b) titrant additions Titrant dispensing velocity: 0.01 and $0.003 \mathrm{~mL} \mathrm{~min}^{-1}$ for (a) and (b), respectively.

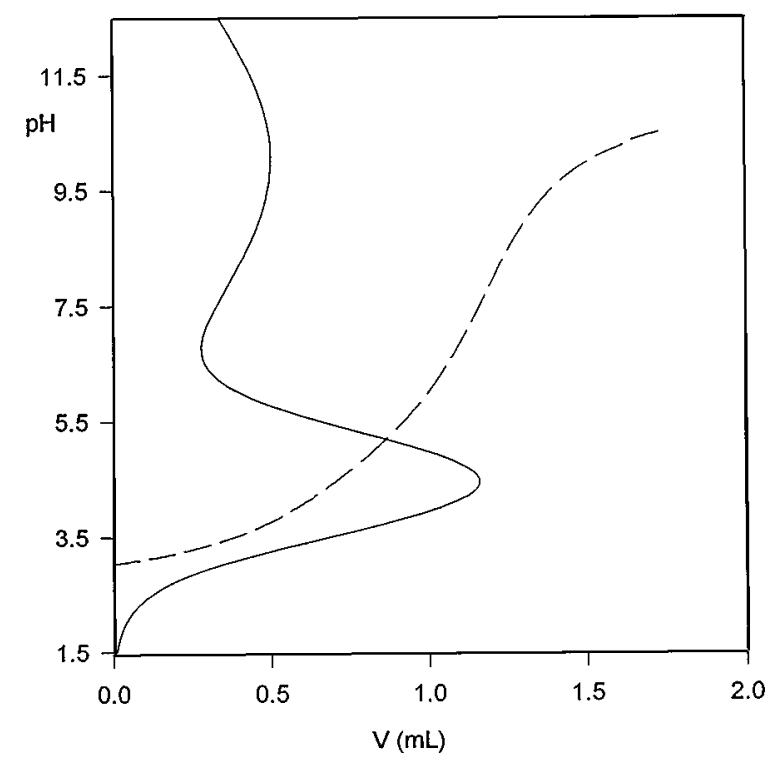

Fig. 4. Titration curve of a $600 \mathrm{ppm} \mathrm{HA}_{50}$ solution (dashed line), together with the computed $\mathrm{pK}_{\mathrm{a}}$ distributions of the relevant acidic functionalities (continuous line). Dispensing velocity of the $0.05 \mathrm{M}$

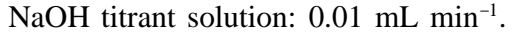

reliability of the data picked up at alkaline $\mathrm{pH}$ affects the values of the parameters drawn out by application of the bimodal distribution model, not only as far as the group of higher $\mathrm{pK}_{\mathrm{a}}$ values is concerned, but also, even if to a minor extent, as to the $\mathrm{pK}_{\mathrm{a}}$ distribution with the lower values, since the fitting procedure works on the titration curve as a whole. Consequently, though the parameters of the distribution with higher $\mathrm{pK}_{\mathrm{a}}$ values, that, as an additional drawback, have to be worked out using a smaller number of titration points, are not completely reliable, also those of the first distribution may be altered. With the aim to reduce the effect of the noisy factors altering the alkaline portion of the titration curve, the first $\mathrm{pK}_{\mathrm{a}}$ distribution of the FA fractions has been also elaborated according to a single Gaussian distribution, suitably limiting the $\mathrm{pH}$ range of observation (see Tabs. III and IV). No significant difference can be evidenced between the $\mathrm{pK}_{\mathrm{A}, 1}$ values resulting from the application of the two models.

From the examination of the parameters of the distributions it can be drawn out that the mean $\mathrm{pK}_{\mathrm{A}}$ values of the two classes of functional groups are consistent with the known properties of carboxyl (mean $\mathrm{pK}_{\mathrm{A}}$ value $=4.5$ ) and phenolic groups $\left(\right.$ mean $\mathrm{pK}_{\mathrm{A}}$ value $\left.=10.0\right)$, respectively [3] . In our case it is difficult to assess the significance of $\sigma_{1}$ and $\sigma_{2}$, due to their high variability, except for the fact that they are indicative of fairly wide ranges of the values in both structural classes.

The $\mathrm{HA}_{300}$ fraction has been studied performing both direct and reverse titrations with different titrant dispensing velocity, and by varying the ionic strength of the solution (see Tab. II). The relative differences between the $\mathrm{pK}_{\mathrm{A}}$ values of the first distribution of acidic functional groups calculated from forward and backward titrations is greater when the titrant addition is slower; this behaviour is apparently singular, but it is actually well in agreement with the different, however slow, rate of the acid-base equilibria in these complex polyelectrolytes, conditioned by the above mentioned conformational changes. Kinetic aspects have been recognised to play a basic role in a similar context, regarding complexation reactions of HS with metals [18].

The effect of varying the ionic strength of the solution is that lower $\mathrm{pK}_{\mathrm{A}}$ mean values are obtained for higher inert salt concentrations. This result is consistent with the observation that the ionisation of acidic groups is usually influenced by electrostatic forces: an higher concentration of cations reduces the intramolecular repulsions due to the negative electric charges deriving from deprotonation of acidic sites, so favouring the deprotonation of the acidic groups. Moreover, the $\mathrm{pK}_{\mathrm{A}}$ values obtained on the basis of the 
Table II. Mean values and relevant standard deviations obtained for the two $\mathrm{pK}_{\mathrm{a}}$ distributions for the different HA fractions.

\begin{tabular}{|c|c|c|c|c|c|}
\hline $\begin{array}{l}\text { sample, } \\
I\left(\mathrm{~mol} \mathrm{~L}^{-1}\right)\end{array}$ & $\begin{array}{l}\text { Dispensing velocity } \\
\quad\left(\mathrm{mL} \mathrm{\textrm {min } ^ { - 1 } )}\right.\end{array}$ & $p K_{A, 1}\left(\sigma_{1}\right)$ & $p K_{A, 2}\left(\sigma_{2}\right)$ & $\begin{array}{c}{[L]^{(a)}} \\
\left(m m o l g^{-1}\right)\end{array}$ & $\sum_{i} r_{i}^{2}{ }^{(b)}$ \\
\hline $\mathrm{HA}_{300} \uparrow, I=0.05$ & 0.01 & $4.59(1.28)$ & $10.70(1.99)$ & 3.8 & 0.36 \\
\hline $\mathrm{HA}_{300} \downarrow, I=0.05$ & 0.01 & $4.40(1.57)$ & $11.00(3.11)$ & 3.7 & 0.27 \\
\hline $\mathrm{HA}_{300} \uparrow, I=0.005$ & 0.01 & $5.19(1.91)$ & $10.57(0.75)$ & 3.9 & 0.16 \\
\hline $\mathrm{HA}_{300} \downarrow, I=0.005$ & 0.01 & $5.31(1.74)$ & $10.83(1.18)$ & 3.5 & 0.14 \\
\hline $\mathrm{HA}_{300} \uparrow, I=0.05$ & 0.003 & $4.76(1.83)$ & $10.80(0.98)$ & 4.1 & 0.33 \\
\hline $\mathrm{HA}_{300} \downarrow, I=0.05$ & 0.003 & $4.07(1.93)$ & $10.00(2.17)$ & 3.9 & 0.32 \\
\hline $\mathrm{HA}_{300} \uparrow, I=0.005$ & 0.003 & $4.82(1.67)$ & $11.07(1.99)$ & 3.6 & 0.23 \\
\hline $\mathrm{HA}_{300} \downarrow, I=0.005$ & 0.003 & $5.42(1.50)$ & $11.35(2.0)$ & 3.7 & 0.45 \\
\hline $\mathrm{HA}_{100} \uparrow, I=0.05$ & 0.01 & $4.79(1.19)$ & $10.00(1.41)$ & 4.0 & 0.36 \\
\hline $\mathrm{HA}_{100} \downarrow, I=0.05$ & 0.01 & $4.76(1.34)$ & $10.02(1.51)$ & 4.1 & 0.28 \\
\hline $\mathrm{HA}_{50} \uparrow, I=0.05$ & 0.01 & $4.41(0.90)$ & $10.07(2.76)$ & 4.5 & 0.36 \\
\hline $\mathrm{HA}_{50} \downarrow, I=0.05$ & 0.01 & $4.39(1.38)$ & $10.10(2.11)$ & 4.6 & 0.18 \\
\hline
\end{tabular}

${ }^{(a)}$ mmoles of total acidic functional groups per gram of freeze dried substance; ${ }^{(b)}$ sum of the squared deviations between experimental and computed points - parameter accounting for the relative goodness of fit between experimental and theoretical curves; $\uparrow$ titration performed with NaOH, on a previously acidified solution; $\downarrow$ titration performed with $\mathrm{HCl}$, on a previously basified solution.

Table III. Results obtained by elaboration of experimental data for FA using a bimodal Gaussian distribution model.

\begin{tabular}{cccccc}
\hline sample & $P K_{A, I}\left(\sigma_{l)}\right.$ & $p K_{A, 2}\left(\sigma_{2}\right)$ & $\begin{array}{c}{\left[L_{1}\right]^{(a)}} \\
\left(\mathrm{mmol} \mathrm{g}^{-1}\right)\end{array}$ & $\begin{array}{c}{\left[L_{2}\right]^{(b)}} \\
\left(\mathrm{mmol} \mathrm{g} \mathrm{g}^{-1}\right)\end{array}$ & $\sum_{i} r_{i}{ }^{(c)}$ \\
\hline $\mathrm{FA}_{\text {total }} \uparrow$ & $4.02(1.22)$ & $10.25(2.41)$ & 3.5 & 2.7 & 0.23 \\
$\mathrm{FA}_{20} \uparrow$ & $3.89(1.41)$ & $10.56(2.49)$ & 3.2 & 2.7 & 0.19 \\
$\mathrm{FA}_{10} \uparrow$ & $4.04(1.28)$ & $10.80(2.48)$ & 3.7 & 3.1 & 0.22 \\
$\mathrm{FA}_{5} \uparrow$ & $3.73(1.57)$ & $10.53(2.05)$ & 3.7 & 2.2 & 0.16 \\
$\mathrm{FA}_{1} \uparrow$ & $3.87(1.30)$ & $10.51(2.18)$ & 4.1 & 2.4 & 0.22 \\
FA $_{0.5} \uparrow$ & $2.97(1.83)$ & $11.37(2.10)$ & 4.2 & 2.2 & 0.13 \\
\hline
\end{tabular}

The solutions were acidified in advance and a basic titrant was then used. The dispensing velocity was $0.03 \mathrm{~mL} \mathrm{~min}{ }^{-1} . I=0.05 \mathrm{~mol} \mathrm{~L}^{-1}$ mmoles of acidic functional groups per gram of freeze-dried matter: (a)belonging to the first distribution; (b) belonging to the second distribution; ${ }^{(c)}$ sum of the squared deviations between experimental and computed points.

Table IV. Results obtained by elaboration of experimental data for FA using a single Gaussian distribution model.

\begin{tabular}{cccc}
\hline $\begin{array}{c}\text { sample, } \\
0.05\left(\mathrm{~mol} \mathrm{~L}^{-1}\right)\end{array}$ & $p K_{A, I}\left(\sigma_{l}\right)$ & $\begin{array}{c}{\left[L_{l}\right]^{(a)}} \\
\left(\mathrm{mmol} \mathrm{g}^{-1}\right)\end{array}$ & $\sum_{i} r_{i}^{2}{ }^{(b)}$ \\
\hline FA $_{\text {total }} \uparrow$ & $3.98(1.17)$ & 4.3 & 0.14 \\
$\mathrm{FA}_{20} \uparrow$ & $4.03(1.42)$ & 4.4 & 0.20 \\
$\mathrm{FA}_{10} \uparrow$ & $4.11(1.26)$ & 4.8 & 0.20 \\
FA $_{5} \uparrow$ & $3.86(1.57)$ & 4.5 & 0.12 \\
FA $_{1} \uparrow$ & $3.89(1.23)$ & 5.1 & 0.25 \\
FA $_{0.5} \uparrow$ & $3.03(1.88)$ & 5.6 & 0.13 \\
\hline
\end{tabular}

Computations were performed only using the acidic part of the titration curve. The dispensing velocity was $0.03 \mathrm{~mL} \mathrm{~min}^{-1}$. $I=0.05 \mathrm{~mol} \mathrm{~L} \mathrm{~L}^{-1}$. (a) mmoles of acidic functional groups per gram of freeze-dried matter - first distribution; (b) sum of the squared deviations between experimental and computed.

backward titration appear to decrease when the ionic strength is high and to increase in the opposite case. This result supports the conclusion that the slow release of hydrogen ions from HA in alkaline solution is favoured by the presence of cations balancing the negative charges on the molecules.
As to the strength of the more acidic functional groups at varying the molecular weight of the HA and FA fractions, the data reported in tables II and III suggest that the lower the a verage cut-off molecular weight, the stronger the acidic character is. No significant trend can be found in the values of the second $\mathrm{pK}_{\mathrm{a}}$ distribution. Furthermore, an higher concentration of acidic moieties seems to be present in the lowest molecular weight fraction. In particular, as shown in table III for FA fractions, this trend seems to be valid as to the carboxylic acid functional groups. On the other hand, as the literature suggests [3], it is not possible to unambiguously determine the concentration of a particular class of functional groups in a humic substance.

\section{Acknowledgements}

This work has been carried out with the financial support of the University of Bologna.

\section{References}

1. Hayes, M. H. B.; MacCarthy, P.; Malcolm, R. L.; Swift, R. S. The search for structure: setting the scene, in: Humic Substances II, Hayes, M. H. B.; MacCarthy, P.; Malcom, R. L.; Swift, R. S. Eds., Wiley, New York, 1989, Ch. 1; pp 4-31.

2. Schnitzer, M. Humic substances: chemistry and reactions. In: Soil Organic Matter, Schnitzer, M.; Khan, S. U. Eds., Elsevier, Amsterdam, 1978, Ch. 1; pp 1-64.

3. Perdue, E. M.; Reuter, J. H.; Parrish, R. S. A statistical model of proton binding by humus, Geochim. Cosmochim. Acta 1984, 48, 1257-1263.

4. Perdue, E. M.; Lytle, C. R. Distribution model for binding of protons and metal ions by humic substances, Env. Sci. Technol. 1983, 17, 654-660.

5. Francioso, O.; Sanchez-Cortes, S.; Tugnoli, V.; Ciavatta, C.; Sitti, L.; Gessa, C. Infrared, Raman and Nuclear Magnetic Resonance $\left({ }^{1} \mathrm{H},{ }^{13} \mathrm{C}\right.$, and $\left.{ }^{31} \mathrm{P}\right)$ spectroscopy in the study of fractions of peat humic acids, Appl. Spectrosc. 1996, 50, 11651174.

6. Sanchez-Cortes, S.; Ciavatta, C.; Francioso, O.; Govi, M.; Gessa, C. Surface-enhanced Raman spectroscopy of humic acids from peat, 8th Meeting of the International Humic Substances Society, Wroclaw (Poland) 9-14 September, 1996. 
7. Ciavatta, C.; Govi, M.; Vittori Antisari, L.; Sequi, P.; Characterisation of humified compounds by extraction and fractionation on solid polyvinylpyrrolidone, J. Chomatogr. 1989, 509, 141.

8. Ghosh, K.; Schnitzer, M. Macromolecular structures of humic substances Soil Sci. 1980, 189, 266-276.

9. Tonelli, D.; Seeber, R.; Ciavatta, C.; Gessa, C. Extraction of humic acids from a natural matrix by alkaline pyrophosphate. Evaluation of the molecular weight of fractions obtained by ultrafiltration, Fresenius J. Anal. Chem. 1997, 359, 555-560.

10. Manunza, B.; Gessa, C.; Deiana, S.; Rausa, R. A normal distribution model for the titration curves of humic acids, J. Soil Sci. 1992, 43, 127-132.

11. Borggaard, O. K. Experiment conditions concerning potentiometric titration of humic acid, J. Soil Sci. 1974, 25, 189-195.

12. Davis, H.; Mott, C. J. B. Titrations of fulvic acids fractions I: Interactions influencing the dissociation-reprotonation equilibria, J. Soil. Sci. 1981, 32, 379-391.

13. Bowles, E. C.; Antweiler, R. C.; MacCarthy, P. Acid-Base Titration and Hydrolysis of Fulvic Acid from Suwennee River, in: Humic Substances in the Suwennee River, Georgia: Interactions, Properties, and Proposed Structure, Averett, R. C.; Leenheer, J. A.; MacKnight, D. M.; Thorn, K. A. Eds., Denver, 1989; p 209-234.

14. Paxéus, N.; Wedborg, M. Acid-base properties of aquatic fulvic acid, Anal. Chim. Acta 1985, 169, 87-98.

15. Masini, J. C. Evaluation of neglecting electrostatic interactions on the determination and characterization of the ionisable sites in humic substances, Anal. Chim. Acta 1993, 283, 803-810.

16. Cabaniss, S. E. Carboxylic acid content of a fulvic acid determined by potentiometry and aqueous Fourier transform infrared spectrometry, Anal. Chim. Acta 1991, 255, 23-30.

17. Alexeio, L. M.; Godinho, O. E. S.; da Costa, W. F. Potentiometric study of acid-base properties of humic acid using linear functions for treatment of titration data, Anal. Chim. Acta 1992, 257, 35-39.

18. Langford, C. H.; Cook, R. L. Kinetic versus equilibrium studies for the speciation of metal complexes with ligands from soil and water, Analyst 1995, 120, 591-596. 